\title{
Avaliação eletrocardiográfica em cães com erliquiose monocitica
}

\section{Electrocardiographic evaluation in dogs with monocytic ehrlichiosis}

\section{Resumo}

No Brasil, enfermidades infectocontagiosas são as mais prevalentes na casuística de caninos domésticos, sendo a erliquiose monocítica canina, causada pela bactéria Ehrlichia canis, uma das mais graves. Entre os sintomas da doença, os mais descritos pela literatura são: letargia, anorexia, epistaxe, hemorragias, anemia e trombocitopenia. Estudos recentes, contudo, indicam que a doença também está associada a diversos sintomas relacionados a lesões cardíacas. O presente trabalho avaliou cães comprovadamente infectados pela $E$. canis com o emprego do eletrocardiograma antes e após o tratamento padrão com doxiciclina $(10 \mathrm{mg} / \mathrm{kg})$, visando identificar alterações típicas causadas pela doença.

\section{Abstract}

The contagious diseases are the most prevalent in Brazilian domestic canines, and one of the most severe is the monocytic ehrlichiosis, caused by Ehrlichia canis bacteria. Among the symptoms of the disease, the most prevalent are apathy, anorexia, epistaxis, hemorrhage, anemia, and thrombocytopenia. However, recent studies indicate association between the disease and diverse symptoms related to cardiac injuries. This article evaluated dogs undoubtedly infected by $E$. canis through electrocardiogram applied before and after the standard treatment with doxycycline $(10 \mathrm{mg} / \mathrm{kg})$, aiming to identify typical variations caused by the disease. 
Gabriel Bento Ferreira ${ }^{1}$

Maurício Gianfrancesco Filippi²

Antônio Carlos Paes ${ }^{3}$

Maria Lúcia Gomes Lourenço ${ }^{4}$
Rua Engenheiro Botelho Egas, 131, Mandaqui,

São Paulo/SP, CEP: 02416-020

هgabento90@yahoo.com.br

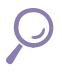

\section{Palavras-chave}

Erliquiose monocítica. Ehrlichia canis.

Eletrocardiograma.

\section{Keywords}

Monocitic ehrlichiosis. Ehrlichia canis.

Electrocardiogram.

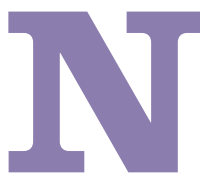

o Brasil, as enfermidades infectocontagiosas transmitidas por carrapatos são de alta prevalência e a erliquiose monocítica canina, causada pela bactéria Ehrlichia canis (pertencente à família Anaplasmataceae), é uma das mais graves e frequentes no acometimento de cães no mundo inteiro (DUMLER et al., 2001).

Ehrlichia sp são bactérias gram-negativas, pleomórficas, de forma cocóide e intracelulares obrigatórias. Em seu sequenciamento genético foi identificado um cromossomo único circular, relativamente menor quando comparado a outras espécies do mesmo gênero, contendo apenas 948 genes (WOODY; HOSKINS, 1991).

Graduado na Universidade Estadual Paulista (Unesp), Botucatu/SP, Brasil. Clínico geral na Clínica Veterinária Cão Maravilha, São Paulo/SP, Brasil. Médico-veterinário na ONG Catland, São Paulo/SP, Brasil.

2 Pós-graduando em Clínica Veterinária (Unesp) Botucatu/SP, Brasil.

3 Docente adjunto, Departamento de Higiene Veterinária e Saúde Pública (Unesp), Botucatu/SP, Brasil.

4 Docente do Departamento de Clínica Veterinária (Unesp), Botucatu/SP, Brasil. 
A transmissão da Ehrlichia canis é efetuada pela picada de carrapato infectado com a bactéria, o que justifica sua alta prevalência em países tropicais e subtropicais, devido à distribuição geográfica do vetor artrópode primário. De fato, o conhecimento dos transmissores competentes assim como dos hospedeiros reservatórios determinam as localizações onde a doença pode ser observada (ANDEREG; PASSOS, 1999).

Não apenas no Brasil, como em todo o mundo, os vetores primários para a transmissão da doença são os carrapatos do gênero Rhipicephalus sanguineus, encontrados preferencialmente em áreas urbanas e, em menor densidade, em áreas rurais. A transmissão é efetuada sob a forma transestadial durante o repasto sanguíneo no cão, não sendo experimentalmente comprovada a transmissão transovariana (BREMER et al., 2005; COHN, 2003).

Quando a E. canis é inoculada pelo carrapato no organismo do hospedeiro vertebrado, a bactéria é fagocitada por macrófagos do sistema mononuclear fagocitário onde se multiplica por fissão-binária em vacúolos isolados ligados à membrana da célula e permanece protegida contra os mecanismos de defesa do sistema imune do hospedeiro, podendo ser liberada para infectar novas células quando há a ruptura da membrana celular em estágios tardios de formação de mórula (RODRIGUES-VIVAS; ALBORNOZ; BOLIO, 2005).

O período de incubação da erliquiose pode variar de 8 a 20 dias, e a doença é dividida em três fases: a primeira, descrita como aguda, é caracterizada por sinais clínicos multissistêmicos como depressão, letargia, anorexia, perda de peso, pirexia, linfadenomegalia, descarga nasal e ocular, esplenomegalia e tendências hemorrágicas, como petéquias e equimoses dérmicas. As principais alterações hematológicas são anemia normocítica normocrômica, discreta leucopenia e principalmente trombocitopenia (NEER, 2002).

O período agudo da erliquiose se estende de uma a quatro semanas, a partir da qual o animal pode apresentar boa resposta ao tratamento, culminando em fácil recuperação. Por outro lado, na ausência de tratamento, ou se ele for realizado de forma incorreta, a doença pode evoluir para a fase subclínica (NEER, 2002).

A fase subclínica da erliquiose canina ocorre de seis a nove semanas após a inoculação do agente e se caracteriza pela recuperação dos sinais clínicos. $\mathrm{O}$ animal apresenta apenas trombocitopenia, que pode ocorrer em qualquer fase da doença, bem como leucopenia e anemia persistente nos exames hematológicos. O animal, contudo, ainda pode carrear a E. canis. Cães submetidos à infecção experimental indicaram que, nessa fase, o local com maior concentração da bactéria é o baço; cães esplenectomizados apresentaram uma doença mais leve do que os animais que possuíam baço (BREITSCHWERDT, 2004; VARELA, 2003).

Da fase subclínica a erliquiose canina pode evoluir para a fase crônica - a mais grave -, caracterizada por hipoplasia medular, pancitopenia, hipocalemia, epistaxe e insuficiência renal aguda devido à presença de imunocomplexos circulantes. A evolução para o óbito está relacionada à ocorrência de hemorragias e infecções secundárias (HARRUS et al., 1997).

Atualmente, é conhecido que a vasculite imunomediada desempenha papel central na fisiopatologia da erliquiose canina e pode explicar a maioria das lesões observadas, cuja gravidade pode estar associada à intensidade da atividade imunológica. Além disso, imunocomplexos circulantes foram detectados em cães infectados tanto natural quanto experimentalmente, os quais são relacionados com a ocorrência de glomerulonefrite, poliartrite e uveíte (BAKER; GAUNT; BABIN, 1988; CASTRO et al., 2004; HARRUS et al., 2001).

As alterações hematológicas da erliquiose canina ocorrem principalmente devido às respostas inflamatórias e imunes desencadeadas pela infecção. Os aspectos constatados são: diminuição da contagem de plaquetas causada por consumo, diminuição de sua meia-vida, sequestro esplênico, destruição mediada pelo sistema imune por meio da produção de anticorpos antiplaquetas. Esses aspectos já foram identificados em cães na fase aguda da doença e da citocina, fator de inibição à migração plaquetária produzida por linfócitos expostos a monócitos infectados pela bactéria. A hipoplasia da medula óssea também está relacionada à diminuição da contagem de plaquetas na fase crônica da doença (NELSON; COUTO, 2010).

Há evidências de que a erliquiose canina está relacionada a lesões cardíacas. Greene (2012) observou altos índices de troponina cardíaca I, um biomarcador importante que detecta lesões do miocárdio em cães que estejam na fase aguda da doença. Também constatou a existência de associação entre a infecção por Ehrlichia canis com alterações cardiovasculares, como hemorragia endocárdica e epicárdica, apesar de ainda não estar comprovado se essas lesões seriam decorrentes de ação direta da bactéria ou se seriam 
secundárias à coagulação intravascular disseminada ou síndrome da resposta inflamatória sistêmica presente em quadros graves (KITTLESON, 1998; PRICE; SAYER, 1983).

Diniz (2006) investigou 194 cães com hemoparasitoses, entre elas a erliquiose monocítica, e os resultados obtidos destacaram a presença de $E$. canis como fator de risco para a ocorrência de lesões miocárdicas, como petéquias e necrose, além da presença de alterações eletrocardiográficas, das quais as mais frequentes foram taquicardia sinusal $(7,7 \%)$, desvio de eixo elétrico médio do complexo QRS à direita (11,5\%), bloqueio de ramo direito do feixe de His $(2,9 \%)$ e aumento da onda $\mathrm{T}(8,7 \%)$.

A eletrocardiografia (ECG) é um exame complementar não invasivo que auxilia na avaliação da atividade elétrica do coração. Pode ser usado para diversos objetivos, como avaliações pré-operatórias e identificação de diversas afecções cardíacas e extracardíacas. É o melhor meio para detectar distúrbios de ritmo e condução elétrica, podendo se tornar uma opção alternativa para a avaliação clínica da erliquiose monocítica canina, além de seu valor no prognóstico no curso da doença (CAMACHO; PEREIRA, 1999).

\section{Metodologia}

Foram utilizados 20 cães atendidos pelo Serviço de Moléstias Infecciosas da Faculdade de Medicina Veterinária e Zootecnia da Unesp (FMVZ-Unesp), em Botucatu, sem distinção de raça, sexo ou idade, infectados naturalmente pela Ehrlichia canis e diagnosticados com base nos elementos histórico, desenvolvimento clínico da doença, exames laboratoriais e exame de Reação em Cadeia de Polimerase precedida por Transcrição Reversa (RT-PCR) a partir de amostra de sangue (WEN et al., 1997).

Para o grupo controle foram utilizados dez cães de raça, idade e sexo variados, comprovadamente hígidos por exame de sangue, nos quais foram realizados eletrocardiograma sob as mesmas condições estabelecidas para o grupo de animais doentes.

Os animais foram incluídos no projeto com autorização do proprietário e da assinatura do Termo de Consentimento, conforme as regras da Comissão de Ética no Uso de Animais (CEUA) da FMVZ-Unesp, sob o protocolo no $83 / 2014$.

Ao serem atendidos pelo Serviço de Moléstias Infecciosas, foram colhidas amostras de sangue para realização de hemograma simples e exame bioquímico sérico para função hepática e renal, visando descartar outras possíveis doenças concomitantes.
Uma vez enquadrados nos pré-requisitos para participação no experimento, os animais foram encaminhados para a avaliação cardíaca por eletrocardiograma, que foi realizado em dois períodos diferentes:

- Após o diagnóstico como infectados por E. canis e antes da aplicação de qualquer medicação, os animais foram submetidos ao exame eletrocardiográfico e, a seguir, foram tratados com doxiciclina em dose terapêutica $(10 \mathrm{mg} / \mathrm{kg})$ administrada por via oral durante 28 dias.

- Ao fim do tratamento foi realizado novo exame eletrocardiográfico.

O exame eletrocardiográfico foi realizado pelo Serviço de Cardiologia Veterinária. Os animais foram posicionados em decúbito lateral direito, mantendo-se os membros torácicos e pélvicos em ângulo reto ao eixo longitudinal da coluna vertebral. A contenção foi efetuada manualmente e os exames realizados em ambiente tranquilo, silencioso e em temperatura ambiente. Os eletrodos foram pinças do tipo "jacaré", fixados na pele nas áreas das articulações umerorradioulnar e femorotibiopatelar, como padronizado por Tilley (1992). A velocidade utilizada para a realização dos traçados eletrocardiográficos foi de $50 \mathrm{~mm} / \mathrm{s} \mathrm{com}$ calibração da voltagem de um centímetro para cada milivolts $(1 \mathrm{mV}=1 \mathrm{~cm})$, e o exame foi realizado sem o uso de anestesia ou qualquer outro tipo de sedação. As três derivações bipolares (I, II e III) e as três derivações unipolares aumentadas (aVR, aVL e aVF) foram registradas no plano frontal e as derivações precordiais CV2RL (rV2), CV6LL (V2), CV6LU (V4) e V10 no plano horizontal.

Para interpretação eletrocardiográfica foram avaliados em cada traçado os parâmetros:

- Cálculo da frequência cardíaca;

- Análise da morfologia e polaridade dos complexos $\mathrm{P}, \mathrm{QRS}$ e $\mathrm{T}$ e dos intervalos, com obtenção das medidas de amplitude e duração das respectivas ondas, bem como da duração dos intervalos entre elas (P-R, R-R e Q-T), com o emprego da derivação II. Onda $\mathrm{P}=$ duração (milissegundos) e amplitude (milivolt); intervalo PR (milissegundos); complexo QRS=duração (milissegundos); onda $\mathrm{R}=$ amplitude (milivolts); intervalo QT (milissegundos); polaridade da onda $\mathrm{T}$ (positiva, negativa ou bifásica); segmento ST (supradesnivelamento, infradesnivelamento 
ou isoelétrico). A avaliação do segundo ST foi efetuada considerando-se normal quando supra ou infradesnivelado em $0,1 \mathrm{mV}$, e a onda $\mathrm{T}$ é classificada quanto à sua polaridade, sendo considerada normal quando se apresentava positiva, negativa ou bifásica, e menor que $25 \%$ do QRS;

- Determinação do eixo elétrico cardíaco médio do complexo QRS, no plano frontal, pelo método da perpendicular à derivação do complexo QRS mais isoelétrico, confirmado pelo método do vetor;

- Determinação do ritmo cardíaco segundo Tilley (1992), que estabeleceu critérios para análise sistemática dos traçados eletrocardiográficos em cães, no qual o ritmo normal é o denominado sinusal e o ritmo alterado se designa bradicardia (quando o ritmo de batimentos está diminuindo) ou taquicardia (quando está aumentado). Esta variação rítmica, por sua vez, está relacionada à origem e condutibilidade dos estímulos no coração (arritmias supraventriculares, ventriculares e bloqueios atrioventriculares);

- Descrição da morfologia, frequência e momento dos distúrbios de ritmo e de condução, quando existentes.

Uma análise estatística foi realizada com base nos dados obtidos. Para as variáveis qualitativas foi utilizado o Teste do Qui-quadrado, e para as variáveis quantitativas, a análise de variância de perfil. Para as variáveis quantitativas que apresentaram distribuição normal, foi realizado Teste T de Student para populações dependentes, caso contrário foi utilizado o Teste de Wilcoxon. O nível de significância utilizado foi $5 \%$. O programa computacional de análise empregado foi o Statistical Analysis System 9.2 (2003).

\section{Resultados e discussão}

O ritmo predominante no grupo de cães com erliquiose, em ambos os momentos, foi a arritmia sinusal $(80 \%)$, seguida do sinusal (15\%) e taquicardia sinusal (5\%), sem diferença significativa entre os momentos. Apenas um cão com erliquiose apresentou arritmia prévia ao tratamento (12 escapes juncionais isolados, 93 escapes ventriculares isolados e sete em pares, seis episódios de bloqueio atrioventricular tipo II, 112 episódios de parada sinusal), havendo diminuição da frequência das arritmias e distúrbios de condução (dois episódios de bloqueio atrioventricular tipo II, um episódio de escape juncional) após o tratamento.
No grupo controle, a arritmia sinusal (80\%) também predominou, seguida do ritmo sinusal (15\%) e taquicardia sinusal (5\%).

Quanto à duração e amplitude das ondas e intervalos eletrocardiográficos, não houve diferença significativa entre os animais doentes e o grupo controle em ambos os momentos, exceto pelo intervalo QT dos animais com erliquiose prévia ao tratamento que diferiu em relação aos animais do grupo controle $(\mathrm{p}=0,0191)$.

Os intervalos PR e QT ( $\mathrm{p}=0,0146$ e 0,0037, respectivamente) apresentaram diferenças significativas entre os momentos avaliados, sendo maiores previamente ao tratamento com doxiciclina.

A polaridade da onda $\mathrm{T}$ não apresentou diferença entre os momentos e nem em relação ao grupo controle. No grupo com erliquiose, a polaridade da onda $\mathrm{T}$ foi $40 \%$ bifásica, $40 \%$ positiva e $20 \%$ negativa. $\mathrm{O}$ segmento $\mathrm{ST}$ também não diferiu entre os momentos (antes do tratamento: $1,55 \pm 0,51 \mathrm{mV}$; após: $1,65 \pm 0,48 \mathrm{mV})$. Contudo, detectou-se diferença significativa em relação aos cães do grupo controle $(-0,06 \pm 0,07 ; \mathrm{p}<0,0001)$.

Não houve correlação entre a frequência e o intervalo PR nos cães do grupo controle $(r=0,5700$; $\mathrm{p}=0,0854)$, nem nos do grupo doentes, previamente $(\mathrm{r}=-0,4389 ; \mathrm{p}=0,0528)$ ou após o tratamento $(\mathrm{r}=-0,1904 ; \mathrm{p}=0,4213)$. Constatou-se nos animais do grupo com erliquiose prévia ao tratamento $(\mathrm{r}=-0,5122$; $\mathrm{p}=0,0210)$ a existência de correlação entre a frequência cardíaca e o intervalo QT e ausência de correlação após o tratamento $(\mathrm{r}=-0,3702 ; \mathrm{p}=0,1081)$. Não foi detectada correlação entre essas variáveis nos cães do grupo controle $(\mathrm{r}=-0,3502 ; \mathrm{p}=0,3212)$.

Na comparação inicial dos animais infectados por Ehrlichia canis com os do grupo controle, não foram observadas alterações em relação aos ritmos predominantes, pois em ambos as frequências de arritmias foram idênticas.

Apenas um cão com erliquiose monocítica apresentou alterações relevantes, provavelmente oriundas de uma doença previamente estabelecida. Contudo, após o tratamento, ele apresentou uma relativa melhora das arritmias e dos distúrbios de condução, o que comprova a existência de uma relação entre cardiopatias que se agravam nos casos em que há uma infecção concomitante por Ehrlichia canis.

Na comparação entre os momentos pré e pós-tratamento não foram constatadas diferenças significativas, exceto pelo intervalo PR e QT, que apresentaram comprimento maior antes do tratamento com doxiciclina. 
Os diagnósticos diferenciais para esse aumento são hipocalcemia, hipocalemia, hipotermia e anormalidades do sistema nervoso central. Contudo, uma vez que o quadro clínico, anamnese e exames complementares não apresentaram qualquer alteração para justificar essas condições, pode-se observar então uma possível alteração de origem causal da erliquiose monocítica.

\section{Conclusão}

Neste estudo foram avaliados animais nas fases inicial e aguda da erliquiose canina, o que por sua vez justificaria a ausência de alterações eletrocardiográficas mais graves. Contudo, discretas variações foram observadas entre os animais antes e depois do tratamento, e o único animal que apresentava doença cardíaca preexistente retornou com relativa melhora. Esse fato comprovou que, apesar de os períodos e etiologias não estarem completamente elucidados, a erliquiose monocítica apresenta, de fato, determinado grau de lesão cardíaca.

Dessa forma, o acompanhamento do sistema cardiovascular para cães comprovadamente com erliquiose monocítica canina (especialmente os que apresentem qualquer cardiopatia prévia) se faz necessário visando preservar a saúde do animal. Por ser um exame relativamente simples e de baixo custo, o eletrocardiograma pode ser utilizado como uma importante ferramenta associada ao tratamento da infecção por Ehrlichia canis. Mais estudos visando o aprofundamento no processo de lesão são recomendados. (;)

\section{Referências}

ANDEREG, P. I.; PASSOS, L. M. F. Erliquiose canina: revisão. Revista Clínica Veterinária, São Paulo, v. 4, n. 19, p. 31-38, 1999.

BAKER, D. C.; GAUNT, S. D.; BABIN, S. S. Anemia of inflammation in dogs infected with Ehrlichia platys. American Journal of Veterinary Research, Schaumburg, v. 49, n. 7, p. $1014-1016,1988$.

BREITSCHWERDT, E. B. Riquetsioses. In: ETTINGER, S. J.; FELDMAN, E. C. Tratado de medicina interna veterinária: doenças do cão e do gato. 5. ed. Rio de Janeiro: Guanabara Koogan, 2004. p. 422-429.

BREMER, W. G. et al. Transstadial and intrastadial experimental transmission of Ehrlichia canis by male Rhipicephalus sanguineus. Veterinary Parasitology, Amsterdam, v. 131, n. 1-2, p. 95-105, 2005.

CAMACHO, A. A.; PEREIRA, P. M. Fisiopatogia da insuficiência cardíaca congestiva em pequenos animais. Revista de Educação Continuada em Medicina Veterinária e Zootecnia do CRMV-SP, São Paulo, v. 2, n. 1, p. 34-38, 1999.
CASTRO, M. B. et al. Experimental acute canine monocytic ehrlichiosis: clinicopatological and immunopathological findings. Veterinary Parasitology, Amsterdam, v. 119, n. 1, p. $73-86,2004$.

COHN, L. A. Ehrlichiosis and related infections. Veterinary Clinics: Small Animal Practice, Amsterdam, v. 33, n. 4, p. $863-884,2003$.

DINIZ, P. P. V. P. Miocardite em cães com erliquiose monocítica. 2006. 136 f. Tese (Doutorado em Medicina Veterinária) - Faculdade de Medicina Veterinária e Zootecnia, Universidade Estadual Paulista, Botucatu, 2006.

DUMLER, J. S. et al. Reorganization of genera in the families Rickettsiaceae and Anaplasmataceae in the order Rickettsiales: unification of some species of Ehrlichia with Anaplasma, Cowdria with Ehrlichia and Ehrlichia with Neorickettsia, descriptions of six new species combinations and designation of Ehrlichia equi and 'HGE agent' as subjective synonyms of Ehrlichia phagocytophila. International Journal of Systematic and Evolutionary Microbiology, London, v. 51, n. 6, p. $2145-$ 2165, 2001.

GREENE, C. Ehrlichia and Anaplasma. In: Infectious diseases of the dog and cat. 4. ed. Amsterdam: Elsevier, 2012. p. 227-238.

HARRUS, S. et al. Canine monocytic ehrlichiosis: a retrospective study of 100 cases, and an epidemiological investigation of prognostic indicators for the disease. Veterinary Record, London, v. 141, n. 14, p. 360-363, 1997.

HARRUS, S. et al. Presence of immune-complexes and absence of antinuclear antibodies, in sera of dogs naturally and experimentally infected with Ehrlichia canis. Veterinary Microbiology, Amsterdam, v. 83, n. 4, p. 343-349, 2001.

KITTLESON, M. D. Primary myocardial disease leading to chronic myocardial failure (dilated cardiomyopathy and related diseases). In: KITTLESON, M. D; KIENLE, R. D. Small animal cardiovascular medicine. St. Louis: Mosby, 1998. p. 319-346.

NEER, T. M. Ehrlichia canis: a clinical approach to diagnosis and treatment. Compendium on Continuing Education for the Practicing Veterinarian, Princeton Junction, v. 24, n. 1 (A), p. 15-18, 2002.

NELSON, R. W.; COUTO, C. G. Doenças miocárdicas do cão. In: ___ Medicina interna de pequenos animais. 2. ed. Rio de Janeiro: Guanabara Koogan, 2010. p. 80-90.

PRICE, J. E.; SAYER, P. D. Canine ehrlichiosis. In: KIRK, R. W. (Org.). Current Veterinary therapy VIII. Philadelphia: W. B. Saunders, 1983. p. 1197-1201.

RODRIGUES-VIVAS, R. I.; ALBORNOZ, R. E.; BOLIO, G. M. Ehrlichia canis in dogs in Yucatan, Mexico: seroprevalence, prevalence of infection and associated factors. Veterinary Parasitology, Amsterdam, v. 127, n. 1, p. 75-79, 2005. 
TILLEY, L. P. Essential of canine and feline electrocardiography: interpretation and treatment. 3. ed. Philadelphia: Lea \& Febiger, 1992. $470 \mathrm{p}$.

VARELA, A. S. Tick-borne Ehrlichiae and Rickettsiae of dogs. In: BOWMAN, D. D. Companion and exotic animal parasitology. Ithaca: International Veterinary Information Service, 2003. [n.p.] Disponível em: <http://www.ivis.org/advances/Parasit_ Bowman/varela/chapter.asp?LA=1>. Acesso em: 14 maio 2014.
WEN B. et al. Comparison of nested PCR with immunofluorescent-antibody assay for detection of Ehrlichia canis infection in dogs treated with doxycycline. Journal of Clinical Microbiology, Washington, DC, v. 35, n. 7, p. 18521855, 1997.

WOODY, B. J.; HOSKINS, J. D. Ehrlichial diseases of dogs. Veterinary Clinics: Small Animal Practice, Amsterdam, v. 21, n. 1, p. 75-98, 1991. 